\title{
Alcoholism and Alcoholic Psychoses Trends in Late-Soviet and Post- Soviet Russia
}

\section{Y E Razvodovsky*}

\author{
International Academy of Sobriety, Russia
}

*Corresponding author: Y E Razvodovsky, International Academy of Sobriety, 80 Gorky Street, Grodno 230009, Belarus, Tel: 37501527018 84, E-mail: razvodovsky@tut.by, yury_razvodovsky@mail.ru

Alcoholism (alcohol dependence) is one of the most common psychiatric disorders in many European countries [1]. Russia has one of the highest incidence of alcoholism and alcoholic psychoses in Europe [1], which may be explained by high overall population drinking and prevalence of irregular heavy drinking of vodka [2-4]. Some estimates suggest that a total number of alcoholics (alcoholdependent individuals) in the late-Soviet Russia were ranging between 23 and 28 millions [5]. Currently, there are approximately 5 million alcoholics in Russia, and the number of heavy drinkers is three to four times that number [2]. Previous findings based on Russian data suggest that the incidence of alcoholic psychoses is considered to be one of the most reliable indicators of alcohol-related problems closely correlating with population drinking [6]. At the same time, the incidence of alcoholism shows no correlation with the level of alcohol consumption per capita. Instead, it correlates positively with the number of doctors-narcologists (a doctor who specializes in narcology) [7].
The aim of the present paper was to discuss the trends in the incidence of alcoholism and alcoholic psychoses in late-Soviet and post-Soviet Russia in relation to social changes, quality of health care and the laws regulating production and sales of alcohol. Here we specified the number of alcohol dependent patients without alcoholic psychoses and the number of alcohol dependent patients with alcoholic psychoses, witches was admitted to hospital for the first time as incidence of alcoholism and incidence of alcoholic psychoses. The data on alcoholism/alcoholic psychoses incidence rates (per 100.000 of the population) are taken from the Russian State Statistical Committee (Rosstat) reports (http://www.gks.ru/).

The trends in the alcoholism and alcoholic psychoses incidence rates in Russia during the late-Soviet and post-Soviet period are displayed in Figure 1. The graphical evidence suggests that the temporal pattern of alcoholism and alcoholic psychoses incidence rates differ markedly. As can be seen, the alcoholic psychoses

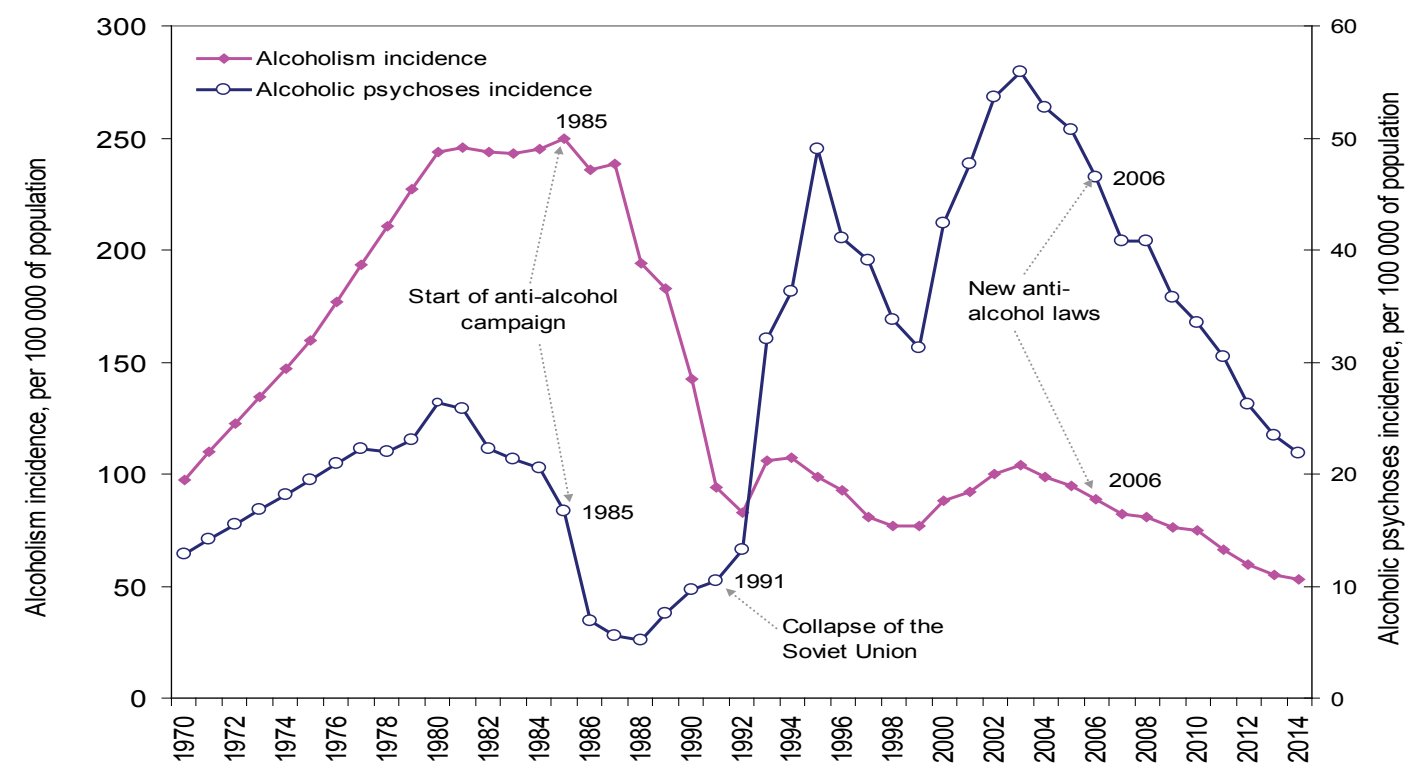

Figure 1: Trends in alcoholism and alcoholic psychoses incidence rates in Russia between 1970 and 2014. 
incidence rates fluctuated greatly over the period: increased substantially during 1970s, decreased markedly from 1980 to 1984 , dropped sharply between 1984-1987, than started on an upward trend from 1987-1992, before jumping dramatically during 1992 to 1995. From 1995-1998 there was a fall in the rates before they again jumping between 1998 and 2003 and then started to decrease in the most recent years. The incidence of alcoholism increased dramatically during 1970s reaching its peak in 1980, and then dropped sharply between 1987 and 1992. There were also spikes in the incidence of alcoholism in 1994 and 2003.

The trend in alcoholic psychoses incidence rates coincide with major social events. Recent Russian history can be divided into several major periods: 1) the late-Soviet period of general stagnation, associated with Brezhnev era, 2) the period of perestroika and Gorbachev's anti-alcohol campaign in the mid-1980s, 3) the political and economic transition following the breakup of the Soviet Union in $1991,4)$ the worsening economic situation associated with financial crisis in 1998, 5) the period of economic growth over the last decade.

During the last decades, Soviet and later Russian governments adopted a series of measures in an attempt to curb the alcoholrelated burden. In 1972 a resolution by the Communist Party Central Committee "About the Measures Restricting Alcohol Consumption" was passed [5]. According to the document, the production of vodka and the number of shops selling it were to be cut. In 1974, the Russian Federation Supreme Soviet ratified a decree creating a system of special institutions (medical-labor dispensaries) within the Ministry of Internal Affaires for the long-term compulsory treatment of advanced alcoholics manifesting antisocial behavior [8]. Noncriminal alcoholics, who violate "labor discipline, public order, and the rules of social community", could be committed for one- to two-year in these explicitly penal institutions.

Despite these efforts, during the 1970s, there was a dramatic growth in the incidence of alcohol dependence reported by official statistics. To some extent this growth reflects the active development of the narcological service, which was officially created in 1976 according to the Order of the Ministry of Health of the USSR No. 131 [8]. Before 1976, narcological assistance to alcohol-dependent patients was made by psychiatrists in the structure of general psychiatric clinic. Since 1976, the narcological service grew rapidly, reaching its peak of funding and access to resources during the antialcohol campaign in 1985-1988. This led to the creation of the narcological in-patient and out-patient departments, as well an increase in the number of specialists in the field of narcology [5]. The overall structure of the narcological care system in post-Soviet Russia had not changed significantly since the 1970s. In general, it presented by two main types of facilities that organized according to administrative and territorial boundaries: the outpatients clinic (dispensary) and hospital, which generally provide care for the population residing in a specific territory.

Gorbachev's anti-alcohol campaign in the 1985-1988 is the most well-known natural experiment in the field of alcohol policy [8]. It seems obvious that sudden decline in alcoholic psychosis incidence during this time appears to be entirely due to anti-alcohol campaign that significantly reduced alcohol consumption by limiting its manufacture and availability [4]. The collapse of the Soviet Union and the ending of the state's alcohol monopoly in January 1992 were accompanied by a sharp rise in alcohol consumption and alcoholic psychoses incidence rates [2].

It is possible that increase in alcoholic psychoses incidence rates in Russia in the mid-1990s, at least partly, is a consequence of deterioration in the quality of health care system, following the collapse of Soviet Union in late 1991 [8]. A process of destruction of the state-funded narcological service that began in 1989 continued in the 1990s [9]. During the 1990s, several important changes linked to broader post-Soviet socioeconomic transformation had significant effect on the addiction treatment system. In connection with the dismantling of the Soviet administrative economy generally and the restructuring of the health care sector in particular, the narcological service experienced the budgetary cutbacks [10]. In relation to this the total number of hospital beds has decreased and the length of stay in hospital has shortened. Shortages of medications and healthcare professionals were also common [8]. During this time state-run narcological service found itself competing with an "alternative medicine". As part of the freedom granted entrepreneurial efforts, there arose private narcological help, which worked on a principle of anonymity. The negative side of this private sector was that is had a single contact with alcoholics, which is a poor basis for lasting remission.

Other changes came with the abolishment of compulsory treatment laws and the commercialization of narcology [9]. After the collapse of the Soviet Union, Russia had moved to dismantle the punitive element of the narcological system and medicallabor dispensaries were formally disbanded in 1994 [8]. The commercialization was directly linked to treatment methods such as "chemical isolation" (implantation of disulfiram), and a type of hypnosis known as emotional-stress psychotherapy or "coding" which use the fear of death to prevent the patient from drinking [10]. These treatment methods represented the main sources of additional income for physicians working in the state-run network [8]. Many other aspects of alcoholism treatment in Russia had been radically re-formed during the 1990s. In particular, anonymous forms of treatment have become much more popular [10]. It should be noted that these changes could be partially explained by a shift in treatment practices from long-term to short-term in-patients treatment and from in-patient to out-patient treatment [9].

Official statistics appear to show a gradual decrease in the incidence of alcoholism since 1987. However, many experts believe that these trends are misleading and that the incidence of alcohol dependence is actually increasing $[7,11]$. The fact that official statistics on alcoholism are misleading could be attributable to degradation and disorganization of narcological service. It should be stated that the rates of alcoholism incidence is influenced by a number of factors. In particular, it is influenced by sharp decrease in the number of staterun narcological clinics and doctors [7]. Besides, due to expansion of anonymous forms of treatment, a significant part of alcoholics failed to get registered at narcological establishments. At the same time, patients with alcoholic psychosis practically always undergo inpatient treatment in state-run narcological service [8].

In contemporary Russia, recognizing the central role of alcohol in the mortality crisis President Putin signed the laws regulating production and sale of alcohol production in 2005 [8,12]. These laws contained regulations aimed at controlling the volume and quality of alcohol products and requiring the registration of alcohol production and distribution facilities. The first one, among other issues, introduced new excise stamps from January 1, 2006. After that time, other stamps have been prohibited. The second law significantly increased nominal capital of alcohol market players since July 1, 2006, so that the market became free from small and average players in favor of large producers. Moreover, the law introduced new and more toxic denaturant additives for household alcohol-containing liquids after July 1, 2006 [8].

Since 2003, Russia has experienced steep decline in the alcoholic psychoses incidence rates which might be attributed to the implementation of the alcohol policy reforms, which increased government control over the alcohol market $[11,12]$. This empirical evidence suggests that recent Russian government's attempt to curb the high alcohol-related morbidity and mortality has been at least partially successful. There is, however, some doubt that recent decline in alcoholic psychoses incidence rates in Russia is fully attributable to the alcohol control measures, since downward trend in alcoholic psychoses incidence rates started before the implementation of the alcohol policy reforms.

In conclusion, empirical evidence suggests that the alcoholic psychoses incidence is the reliable indicator of alcohol-related problems at the population level. This evidence also indicates that the alcoholic psychoses incidence is considered to be indicator of 
the efficiency of narcological service regarding early diagnosis and treatment for alcohol dependence. The higher alcoholic psychoses incidence rates, the bigger is the number of alcohol-dependent patients getting into doctor's eyeshot at advanced stages of the disease. The outcomes provide indirect support for the hypothesis that the dramatic fluctuations in the alcoholic psychoses incidence rates in Russia during the last decades were related to the availability/ affordability of alcohol.

\section{References}

1. Anderson P, Baumberg B (2006) Alcohol in Europe. London: Institute of Alcohol Studies.

2. Nemtsov AV, Razvodovsky YE (2008) Alcohol situation in Russia, 19802005. Social and Clinical Psychiatry 2: 52-60.

3. Stickley A, Leinsalu M, Andreew E, Razvodovsky YE, Vagero D, et al. (2007) Alcohol poisoning in Russia and the countries in the European part of the former Soviet Union, 1970-2002. Eur J Public Health 17: 444-449.

4. Stickley A, Razvodovsky Y, McKee M (2009) Alcohol and mortality in Russia:
A historical perspective. Public Health. 23: 20-26.

5. Segal BM (1990) The drunken society - alcohol abuse and alcoholism in the Soviet Union. Hippocrene Books, New York.

6. Razvodovsky YE (2015) The effect of beverage type on alcoholic psychoses rate in Russia. Alcohol Alcohol 50: 200-2005.

7. Averbach YK, Shamota AZ (1992) Potreblenie alcoholia i necotorye pocazately alcoholizacii naselenia. Voprosy narcologii, 2: 33-37.

8. Nemtsov AV (2011) A contemporary history of alcohol in Russia. Stockholm, Sodertorns hogskola.

9. Krasnov VN, Gurovich I (2012) History and current condition of Russian psychiatry. Int Rev Psychiatry 4: 328-333.

10. Raikhel E (2010) Post-Soviet Placebos: Epistemology and Authority in Russian Treatments for Alcoholism. Cult Med Psychiatry 34: 132-168.

11. Nemtsov A, Razvodovsky YE (2015) Russian alcohol situation in false mirror Sobriology 3: 70-73.

12. Razvodovsky YE (2014) Was the mortality decline in Russia attributable to alcohol control policy? Journal of Sociolomics 3: 2. 